\title{
Developmental Aspects of Renal $\beta$-Amino Acid Transport. III. Ontogeny of Transport in Isolated Renal Tubule Segments
}

\author{
AARON L. FRIEDMAN, ${ }^{(17)}$ DIANE K. JAX, AND RUSSELL W. CHESNEY \\ Pediatric Renal Disease Laboratory, Department of Pediatrics, University of Wisconsin Clinical Science Center, \\ Madison, Wisconsin, USA
}

\begin{abstract}
Summary
Isolated renal tubules were prepared from newborn and adult Sprague-Dawley rats. They were used to study the uptake and accumulation of the $\beta$-amino acid, taurine, by renal epithelium. Initial rate as well as steady-state kinetics were studied. Initial rate studies revealed heterogeneity of uptake in newborn and adult tubules. Slower uptake was present in the newborn in the lowafinity system. Slowed efilux was found in neonatal tissue. Newborn tubules in contrast to adult tubules demonstrated uptake under anaerobic conditions. Adult and newborn tissues showed decreased uptake of taurine when incubated with $\beta$-alanine. Physiologic taurinuria, be it in the rat or man, may be due to less rapid initial uptake and/or slowed efilux from renal epithelium.
\end{abstract}

\section{Speculation}

$\beta$-Amino acid transport by newborn rat renal epithelium varies from that of adult rat renal epithelium. Although heterogeneity of uptake exists in both, newborn uptake by and efilux from renal epithelium is slower, and intracellular levels are higher in the newborn. Uptake differences may be examined by luminal membrane preparations; however, slowed efflux and higher intracellular levels suggest studies on intracellular components and basal lateral membranes are warranted.

A physiologic aminoaciduria has been observed in the newborn of many mammalian species, including man (14). The rat, whose pattern of neonatal aminoaciduria somewhat resembles man's has been used by many investigators to study amino acid transport processes by the kidney (8). Recently, a number of laboratories, including ours, have studied the ontogeny of amino acid transport using rat renal cortex slices $(5,6)$. However, results of cortical slice studies have been somewhat contradictory, particularly for glycine and imino acid transport $(11,13)$. Furthermore, cortex slices from neonatal kidneys may be difficult to prepare, and the thickness of adult or neonatal cortex slices does not permit determination of initial rate kinetics.

Taurine, which is inert in rodent renal tissue, has been used to study $\beta$-amino acid transport across renal epithelium (9). Taurine reabsorption is $95 \%$ of filtered load in the adult rat but only $54 \%$ of filtered load in 2-wk-old rats, thus indicating a neonatal taurinuria (5). Cortical slice studies have demonstrated heterogeneity of uptake in both adults and newborns. However, efflux of taurine from newborn renal epithelium was slower. Further, initial rate of uptake was reduced in immature cortex $(5,6)$. This report describes the properties of taurine transport in isolated tubule segments from neonatal rats and compares these results to values obtained using adult tubule preparations.

\section{METHODS}

Sprague-Dawley rats (150 to $250 \mathrm{~g}$ ) obtained from SpragueDawley Holtzman (Madison, WI) were fed a commercial rat chow
(Lab Blox; Wayne Feeds, Libertyville, IL). Newborn animals (Sprague-Dawley Holtzman, Madison, WI), less than $36 \mathrm{hr}$ old and adult animals were sacrificed by decapitation, and their kidneys were immediately removed. The kidneys were bisected, and the cortex was separated from the medulla. Care was taken to avoid contamination with medullary tissue. The cortical tissue was minced in iced Krebs-Ringer bicarbonate buffer with $0.75 \%$ collagenase as described by Burg and Orloff (4). Cortical tissue underwent digestion for $\mathbf{4 5} \mathrm{min}$ in the collagenase solution under constant gassing with $95 \% \mathrm{O}_{2}-5 \% \mathrm{CO}_{2}$. The resulting suspension was filtered through three layers of surgical gauze (Scholl, Chicago, IL) and spun three times at $1600 \mathrm{rpm}$ with medium to wash away any collagenase. The tubule suspension was brought to the described volume with Krebs-Ringer bicarbonate buffer. Fetal calf serum was added to approximately $1 \mathrm{ml} / 20 \mathrm{ml}$ final volume. Final suspensions contained approximately 10 to $15 \mathrm{mg}$ to tubule wet weight per $\mathrm{ml}$ of adult tissue and 8 to $12 \mathrm{mg}$ of tubules per $\mathrm{ml}$ of newborn tissue. Microscopy of tissue samples revealed predominately long tubule segments with negligible glomerular contamination.

Concentrative uptake studies were performed by a modification of the method of Burg and Orloff (4). Uptake of taurine was determined using the distribution ratios $[\mathrm{cpm} / \mathrm{ml}$ intracellular fluid to $\mathrm{cpm} / \mathrm{ml}$ medium]. Extracellular volume (volume of trapped medium in the pellet) was measured using poly $\left(\mathrm{C}^{\text {l4 }}\right)$ ethylene glycol (7). Extracellular volume subtracted from total tissue water (wet tissue weight minus dry weight after $48 \mathrm{hr}$ of dessication at $110^{\circ} \mathrm{C}$ ) yielded intracellular volume.

Taurine uptake by tubules was carried out at $37^{\circ} \mathrm{C}$ under continuous gassing with $95 \% \mathrm{O}_{2}-5 \% \mathrm{CO}_{2}$. The $\mathrm{pH}$ remained constant during experimental periods. Concentration dependence of uptake for taurine was measured using unlabeled amino acid in concentrations ranging from 0.005 to $20 \mathrm{mM}$ plus $1 \mu \mathrm{Ci}$ of ${ }^{14} \mathrm{C}$ labeled amino acids. Initial rate kinetics were determined after 10 min incubations, whereas steady-state kinetics were measured over $30 \mathrm{~min}$ of incubation in adults and $90 \mathrm{~min}$ of incubation in newborns. Line-weaver-Burk plots were constructed from which "apparent" $K_{m}$ and $V_{\max }$ (maximum velocity) for initial rates and $V_{\text {. (velocity at steady state) were determined. }}$

Intracellular taurine concentrations were ascertained from preparations placed in tared tubes and spun for $10 \mathrm{~min}$ at $16,000 \mathrm{rpm}$ in a Sorvall R2B refrigerated at $4^{\circ} \mathrm{C}$. After removal of a $0.3 \mathrm{ml}$ medium sample, the pellet surface and tube were dried with suction, and the tube was weighed. Tubes were then placed in boiling water for $5 \mathrm{~min}$ to disrupt the pellet, and to denature tissue protein, a $0.3 \mathrm{ml}$ sample was then removed. Both medium and tissue samples were placed in Aquasol and counted.

The uptake of taurine in the presence of other amino acids was assessed by a 30-min incubation of $0.01 \mathrm{mM}$ taurine with $0.1 \mathrm{mM}$ of a number of other amino acids or of $2 \mathrm{mM}$ taurine with $20 \mathrm{mM}$ of the other amino acids. In a separate study, tubules were also incubated under anoxic conditions $\left(95 \% \mathrm{~N}_{2}\right.$ and $\left.5 \% \mathrm{CO}_{2}\right)$. 
Efflux, the rate at which taurine exits from the tubule cell into the surrounding media, was determined after steady state was reached. Tubules were incubated for $30 \mathrm{~min}$ in adults and $90 \mathrm{~min}$ in newborns after which aliquots were sampled to determine intracellular taurine content. This allowed a measurement of efflux during comparable transport conditions. The remaining tissue was centrifuged at $1600 \mathrm{rpm}$, washed twice with fresh buffer, and then resuspended in fresh buffer and fetal calf serum. Samples were taken from this second incubation at various intervals up to $30 \mathrm{~min}$.

The points of the Lineweaver-Burk plots were connected by lines calculated using a Texas Instruments TI58 Computer. Statistical significance was determined by Student's $t$ test, with a $P<$ 0.05 considered statistically significant.

\section{MATERIALS}

Collagenase type II was purchased from Sigma Chemical Co., St. Louis, MO. Radiolabeled $\left[1-{ }^{14} \mathrm{C}\right]$ taurine (specific activity, 56.4 $\mathrm{Ci} /$ mole) and poly[1.2- $\left.{ }^{14} \mathrm{C}\right]$ ethylene glycol (specific activity, 2.3 $\mathrm{Ci} /$ mole) were obtained from New England Nuclear. Boston, MA. Unlabeled amino acids, all of reagent grade, were obtained from Sigma Chemical Co., aside from leucine (Nutritional Biochemicals Co., Cleveland, $\mathrm{OH}$ ) and glycine (Fisher Chemicals, Chicago, IL). Fetal calf serum was purchased from International Scientific Industries, Gary, IL. All chemicals used to prepare media and buffer were reagent grade.

\section{RESULTS}

Water content of adult tissue pellets $(n=20)$ was $80.1 \pm 0.5 \%$ $( \pm$ S.E.). Extracellular volume was $18.3 \pm 0.6 \%$ yielding an intracellular volume of approximately $62 \%$. In the newborn, water content of tissue pellets $(n=6)$ was $84.3 \%( \pm 0.8 \%)$. Extracellular space was $10.5 \pm 0.6 \%$ leaving an approximate intracellular volume of $74 \%$. Uptake of taurine at $0.01 \mathrm{mM}$ reached a steady state at $30 \mathrm{~min}$ in the adult, whereas, in the newborn, uptake of taurine at $0.01 \mathrm{mM}$ approached steady state at $90 \mathrm{~min}(90 \%$ of steadystate value) (Fig. 1). A taurine concentration of $0.01 \mathrm{mM}$ is close to the physiologic range and was used to study taurine uptake over time. At $0.1 \mathrm{mM}$ taurine, steady state in both age groups is reached within $15 \mathrm{~min}$. No concentrative uptake was found with $20 \mathrm{mM}$ taurine.

Figure 2 depicts the velocity of uptake of taurine over the concentration range of 0.01 to $1 \mathrm{mM}$ taurine. During steady state, the velocity of uptake ( $v$ ) is similar in adult and newborn animals. However, in the first $10 \mathrm{~min}$, termed initial rate, uptake is more rapid in the adult than in the newborn.

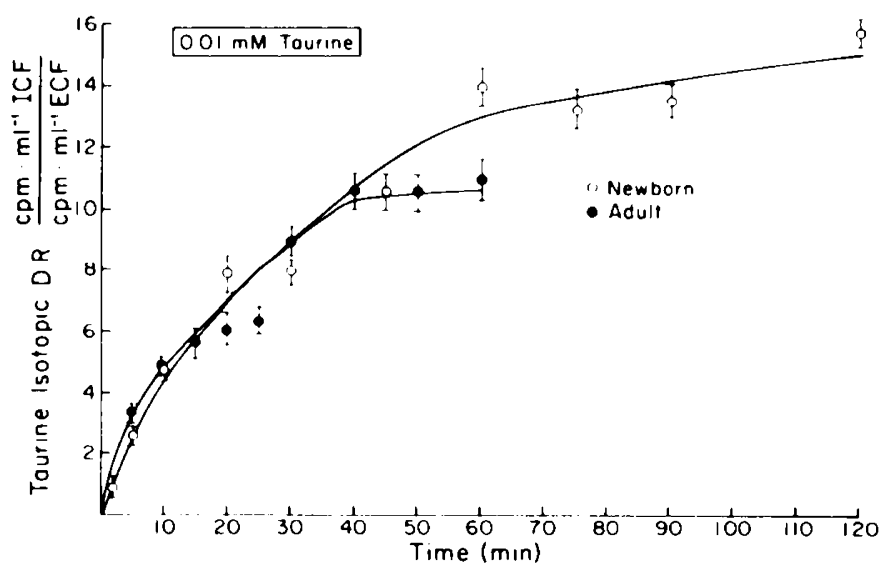

Fig. 1. Time course of taurine accumulation by adult $(\Theta)$ and newborn $(O)$ cortical tubule segments. Points, depicts mean and standard error of at least four determinations. D.R. (distribution ratio), ratio of $\mathrm{cpm} / \mathrm{ml}$ intracellular fluid to $\mathrm{cpm} / \mathrm{ml}$ medium.
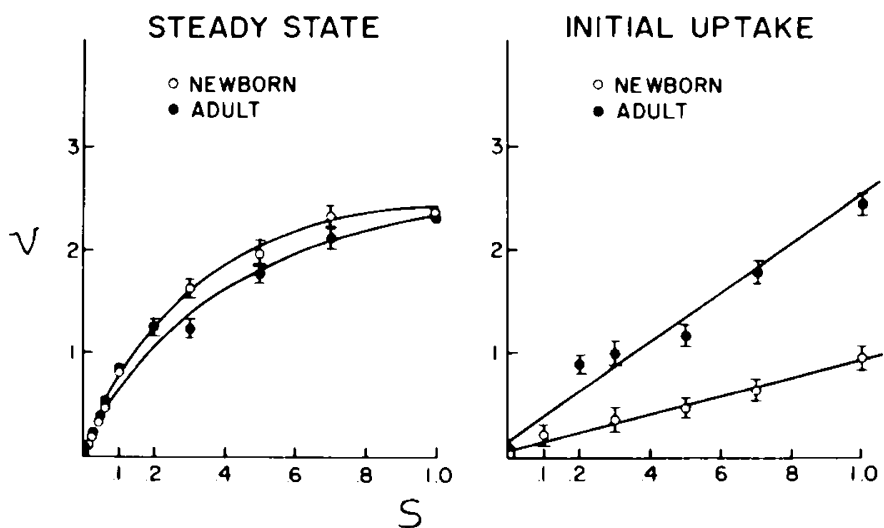

Fig. 2. Velocity of uptake $(V)$ of taurine over concentration $(S)$ range of 0.01 to $1 \mathrm{mM}$ taurine. $\mathrm{V}$ of steady state measured in adult $(O)$ as 10 moles $\cdot \mathrm{ml}^{\prime}$ intracellular fluid. $30 \mathrm{~min}$ and in newborn $O$ as $10^{\text {: }}$ moles. $\mathrm{ml}$ ' intracellular fluid . $90 \mathrm{~min}$. Initial uptake represents 5 -min incubation. Points, mean and standard error of at least four determinations.

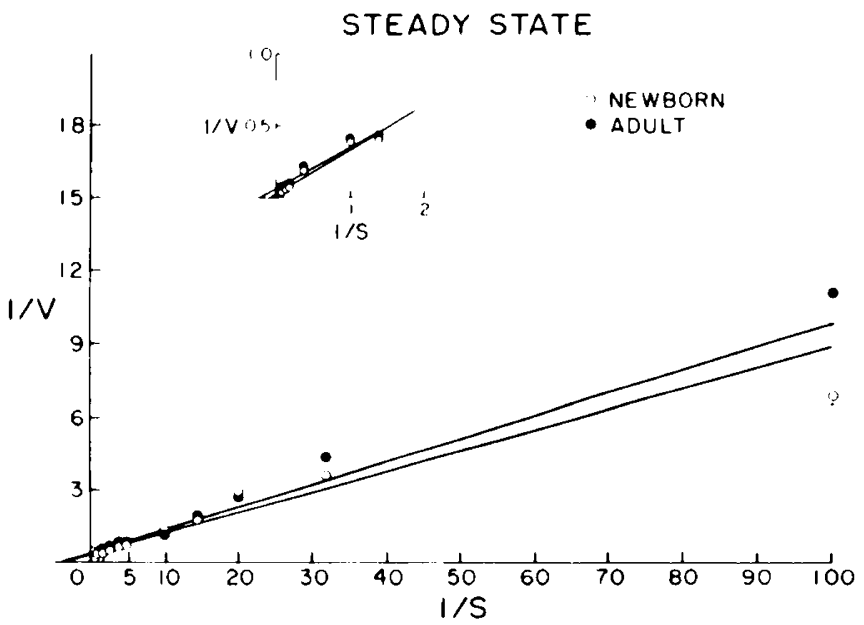

Fig. 3. Lineweaver-Burk double reciprocal analysis of concentrationdependent uptake of taurine. Concentration range was 0.005 to $20 \mathrm{mM}$ and incubation period was $30 \mathrm{~min}$ in adults and $90 \mathrm{~min}$ in newborns. Inset, enlargement of analysis at $1 / \mathrm{S}$ values less than 1.5. Points, derived from at least four determinations. $V$, velocity of transport $\mu$ moles $/ \mathrm{ml}$ intracellular fluid per incubation period); $S$, substrate concentration (mmoles/liter).

Concentration-dependent uptake was studied over an external concentration range of 0.005 to $20 \mathrm{mM}$ taurine. Steady-state calculations were performed after $30 \mathrm{~min}$ incubations in the adult and $90 \mathrm{~min}$ incubations in the newborn. The calculations are depicted in Lineweaver-Burk plots (Fig. 3), and an apparent $\mathbf{K}_{m}$ and velocity for the steady-state $V_{s}$ was determined (Table 1 ). A two-limbed uptake system for adult and newborn tissue was found. However, the apparent $K_{m}$ and $V_{n}$ values were nearly identical and no difference could be found between adult and newborn ( $P$ $>0.1$ ).

Initial rate kinetics were studied over an external concentration range of 0.005 to $20 \mathrm{mM}$ taurine. Initial rate calculations were determined after $10 \mathrm{~min}$ and are depicted on Lineweaver-Burk plots (Fig. 4). An apparent $K_{m}$ and $V_{\max }$ (maximum velocity) were determined and are shown in Table 1 . In this instance, apparent $K_{m}$ 's are essentially identical; however, the maximum velocity is significantly different with respect to the low-affinity (high $\mathbf{K}_{\mathrm{m}}$ ) uptake system $(P<0.001)$.

Efflux of taurine from tubule cells was determined by comparing counts remaining in tissue after incubation in taurine-free medium with counts present in tissue after steady-state incubation in a taurine-containing medium. This technique permitted the determination of percentage of taurine remained in tubule tissue. 
Table 1.'Kinetic rates of taurine accumulation'

\begin{tabular}{|c|c|c|c|c|}
\hline & \multicolumn{3}{|c|}{ Steady state } & \multirow[b]{2}{*}{$V_{N 2}$} \\
\hline & $\mathbf{K}_{m ! 1}$ & $\mathbf{K}_{\mathbf{n i 2}}$ & $V_{-1}$ & \\
\hline Adult & 0.212 & 5.26 & 2.76 & 13.88 \\
\hline$P$ & $>0.1$ & $>0.1$ & $>0.1$ & $>0.1$ \\
\hline \multirow[t]{3}{*}{ Newborn } & 0.36 & 4.58 & 3.78 & 12.55 \\
\hline & \multicolumn{2}{|c|}{ Initial Rate } & & \\
\hline & $\mathbf{K}_{\mathrm{m} 1}$ & $\mathrm{~K}_{\mathrm{m} 2}$ & $V_{\max 1}$ & $V_{\text {mix }}: 2$ \\
\hline Adult & 0.187 & 5.17 & 2.17 & 14.65 \\
\hline$P$ & $>0.1$ & $>0.1$ & $<0.1$ & $<0.001$ \\
\hline Newborn & 0.224 & 4.01 & 0.96 & 5.52 \\
\hline
\end{tabular}

' Data derived by linear regression analysis of points depicted in Figures 2 and $3 . K_{m}$ is measured in mmoles and $V_{\text {, and }} V_{\max }$ are measured in $\mu$ moles per $\mathrm{ml}$ intracellular fluid (ICF) per time period. All lines had correlation coefficient $(r) \geq 0.97$. P's are determined by comparison of regression coefficient and analysis of variance.

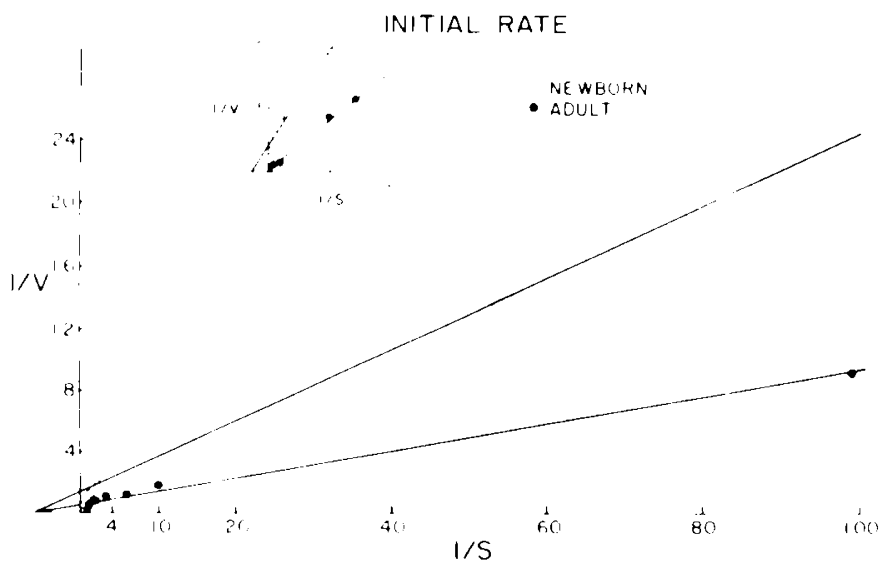

Fig. 4. Lineweaver-Burk double reciprocal analysis of taurine uptake. Concentration range was 0.005 to $20 \mathrm{mM}$ taurine and incubation period was $10 \mathrm{~min}$. Inset, enlargement of analysis at $1 / \mathrm{S}$ values less than 1.5 . Points, derived from at least four determinations. $V$, velocity: $S$, substrate concentrations as noted in Figure 3

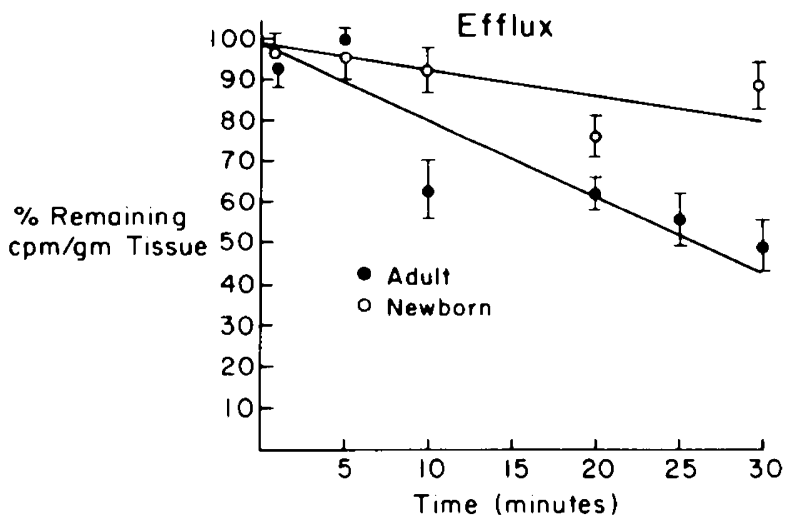

Fig. 5. Efflux of taurine from cortical tubule segments. Ordinate, percentage of taurine remaining in tissue as explained in the text.

Fifty percent of the intracellular taurine remained after $30 \mathrm{~min}$ in the adult. In comparison, approximately $88 \%$ of intracellular taurine remained in newborn tubule cells after $30 \mathrm{~min}$ incubation in a taurine-free medium (Fig. 5).

Studies in which adult preparations were incubated with 0.01 $\mathrm{mM}$ taurine under continuous $95 \% \mathrm{~N}_{2}-5 \% \mathrm{CO}_{2}$ gassing (anoxic conditions) demonstrated a significant reduction in taurine accumulation as compared to uptake under aerobic conditions. With $2 \mathrm{mM}$ taurine, no uptake by adult tissue was seen in a $95 \% \mathrm{~N}$. atmosphere. Using 0.01 or $2 \mathrm{mM}$ taurine, newborn tubules showed no difference in uptake when incubated under aerobic or anaerobic conditions (Fig. 6). Therefore, in the newborn, uptake can occur under anoxic conditions.

Newborn tubules were incubated in taurine along with other amino acids. No effect on the uptake of taurine was found at 0.01 $\mathrm{mM}$ taurine with $0.1 \mathrm{mM}$ cysteine or glutamic acid. A slight increase in taurine $(0.01 \mathrm{mM})$ accumulation was noted with glycine $(0.1 \mathrm{mM})$ and leucine $(0.1 \mathrm{mM})$. With $0.1 \mathrm{mM} \beta$-alanine added to the incubation medium, taurine uptake was decreased by $50 \%(P<0.005)$ (Fig. 7). A similar experiment using $2 \mathrm{mM}$ taurine and $20 \mathrm{mM}$ glycine, glutamic acid, or $\beta$-alanine or $\alpha$ aminoisobutyric acid resulted in decreased uptake ( $20 \%$ of control) when $\beta$-alanine was present $(P<0.005)$. A decrease in taurine uptake was also found with $\alpha$-aminoisobutyric in the medium (60\% of control) $(P<0.1)$. Adult studies using the same experimental design yielded very similar results (10).

\section{DISCUSSION}

The presence of aminoaciduria in neonates and its subsequent disappearance with age has led to extensive examination of the ontogeny of amino acid transport processes within renal epithelium. Studies of glycine transport in newborn cortical slices have

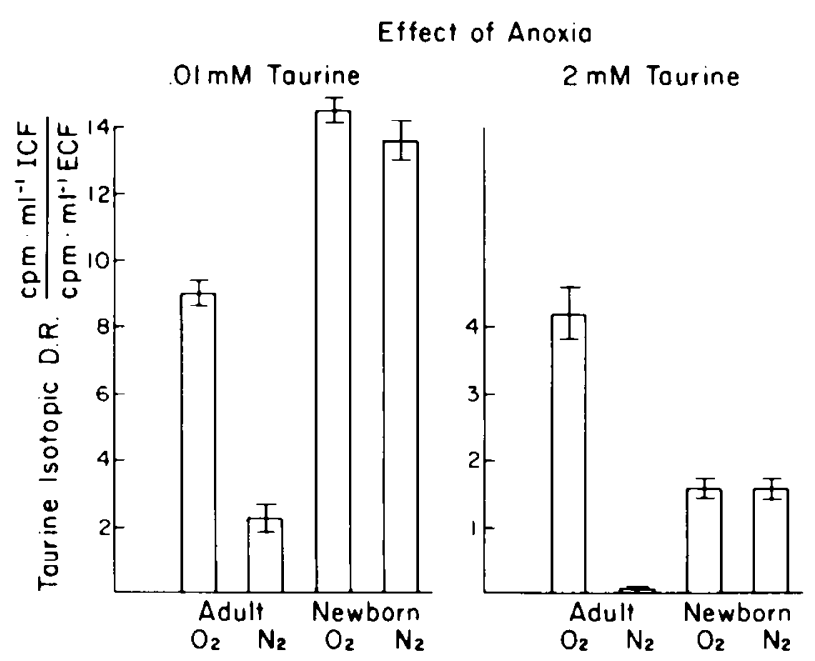

Fig. 6. Effect of incubation under $95 \% \mathrm{~N}-5 \%$ ( $(0)$ atmosphere. Bars. taurine accumulation in cortical tubules after $30 \mathrm{~min}$ incubation in adult and $90 \mathrm{~min}$ incubation in newborn. Taurine concentration in the external medium is noted. Data represents mean $\pm S$.E. of at least four determinations.

\section{Newborn-Effect of Other Amino Acids}

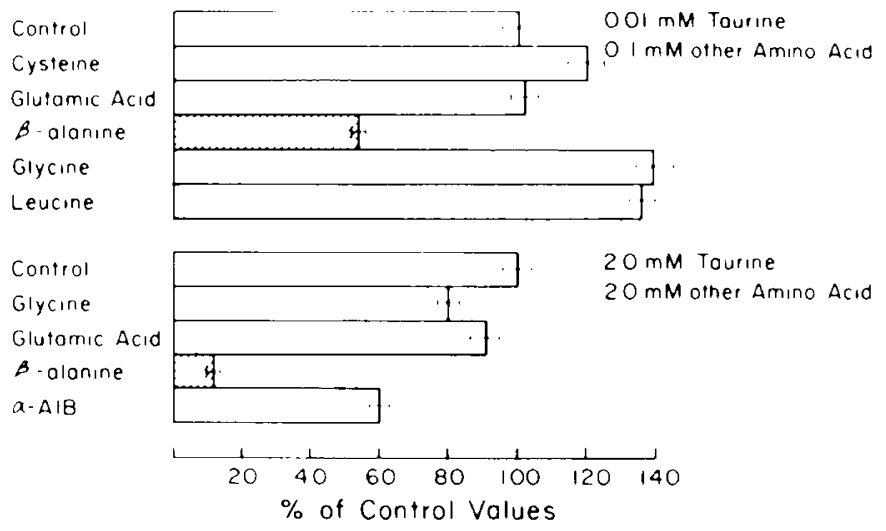

Fig. 7. Effect of separate incubations with taurine at concentrations of 0.01 and $2.0 \mathrm{mM}$ and each of the other amino acids listed at concentrations of 0.1 and $20 \mathrm{mM}$, respectively. Data compared to uptake of taurine alone (control). Bars, mean \pm S.E. of at least four determinations. 
revealed conflicting information. Baerlocher et al. (1-3) showed diminished uptake and lack of a high-affinity uptake system in the newborn Long-Evans rat. Work by Segal et al. (15) using Sprague-Dawley rats revealed glycine uptake systems very similar to the adult. Roth et al. (13) studying glycine accumulation in isolated rat tubule segments found high- and low-affinity uptake systems in both adult and newborn tissue. Efflux of glycine from newborn cells was slower as noted by Segal et al. (15) in cortex slices and confirmed by Roth et al. (13) in isolated tubule preparations.

The ontogeny of $\beta$-amino acid transport has been studied previously in renal cortex slices. Studies from this laboratory using taurine as a model for $\beta$-amino acids clearly demonstrate that renal cortex slices accumulate taurine against a concentration gradient. However, at low concentrations near the physiologic range $(0.01 \mathrm{mM})$, uptake has been shown to continue for at least $240 \mathrm{~min}$ in the newborn (and at least $120 \mathrm{~min}$ in the adult) $(5,6)$. Slice thickness and uneven distribution of medium within slices made initial rate kinetic determinations inaccurate, and because of contradictory results with other amino acids and the difficulty in measuring initial rate kinetics, we investigated the uptake and efflux of taurine from isolated tubule fragments prepared from adult and newborn Sprague-Dawley rats.

Concentrative uptake of taurine occurs in both newborn and adult cortical tubules. During steady state, a two-limbed uptake curve with a low $K_{m}$, high-affinity system and a high $K_{m}$, lowaffinity system was found in tubules as well as in slices. Further, as in slices, the steady-state taurine level in newborn tubules was higher than that seen in adult tubules. Nonetheless, at $0.01 \mathrm{mM}$ taurine concentrations, steady state is reached much earlier in tubules than in slices for both adult $(30 \mathrm{~min})$ and newborn $(90$ min) tissue. Under steady-state conditions, our results showed virtually no difference between the adult and the newborn with respect to the apparent $K_{m}$ and the velocity at the steady state.

Initial rate studies probably permit an analysis of amino acid accumulation when uptake is the predominant transport event. These studies allow for a number of comparisons between adult and newborn tissue. They demonstrated a two-limbed uptake system for taurine in the newborn and the adult tubule. Evaluation of taurine uptake over a wide concentration range clearly demonstrated the presence of both uptake sites in the newborn and adult, as has been noted by Reynolds et al. (12) for glycine accumulation. As can be seen in Figure 2, the velocity of uptake is slower in the newborn than in the adult during the first $10 \mathrm{~min}$ of accumulation. Also as noted in Table 1 , there is a decrease in the initial velocity of uptake for the high $K_{m}$ system. Our studies in slices suggested a slower uptake in neonatal tissue. Reynolds $e t$ al. (12) in studying initial rates of glycine uptake in neonatal tubules found a slowed velocity of uptake with high $\mathrm{K}_{\mathrm{m}}$ system only. We also found a decreased $V_{\max }$, suggesting a slower velocity of uptake in the high $\mathrm{K}_{\mathrm{m}}$ system only.

Studies in cortical slices have suggested that the increased accumulation of taurine in newborn renal epithelium was in part the result of slowed efflux from cells. Our results in isolated tubules confirm this finding. Whereas after $30 \mathrm{~min}, 50 \%$ of the taurine had left tubule cells in the adult preparation only $12 \%$ had left newborn tubule cells in the same time period.

Under anoxic conditions $\left(95 \% \mathrm{~N}_{2}-5 \% \mathrm{CO}_{2}\right)$ a clear difference was noted between adult and newborn tubule segments. Accumulation of taurine was markedly decreased in the adult while in the newborn no effect on the active uptake of amino acid was shown. This resistence to anoxia on the part of newborn tissue has also been reported in cortical slice studies $(3,6)$. The uptake of taurine in newborn tubules was inhibited in the presence of alanine another $\beta$-amino acid in the medium. The slight enhancement of taurine accumulation with leucine and glycine and the slight decrease in uptake of taurine when incubated with $\alpha$-aminoisobutyric acid remain unexplained. In general, however, adult and newborn tubules acted in a similar fashion (10).

In conclusion, $\beta$-amino acid transport was studied in the adult and newborn Sprague-Dawley rat using isolated cortical tubule segments. Tubules permit a more rapid means of evaluating transport. Initial rate kinetics were determined both high- and low-affinity uptake system in adult and newborns. Initial rate studies showed a slowed uptake especially in the high $\mathbf{K}_{\mathrm{m}}$ system. Slowed efflux in newborns was also found. The combination of decreased velocity of uptake and slow efflux may account for the increased accumulation of taurine in renal epithelium. This may play an important role in the aminoaciduria found in newborns. Further, no evidence was found for the appearance of a new transport site because heterogeneity of uptake was apparent at birth.

\section{REFERENCES AND NOTES}

I. Baerlocher, K. E., Scriver, C. R., and Mohyuddin, F.: Ontogeny of iminoglycine transport in mammalian kidney. Proc. Natl. Acad. Sci. U. S. A., 65: 1009 (1970).

2. Baerlocher, K. E., Scriver, C. R., and Mohyuddin, F.: The ontogeny of amino acid transport in rat kidney. I. Effect on distribution ratios and intracellular metabolism of proline and glycine. Biochim. Biophys. Acta, 249: 353 (1971).

3. Baerlocher, K. E., Scriver, C. R., and Mohyuddin, F.: The ontogeny of amino acid transport in rat kidney. II. Kinetics of uptake and effect of anoxia. Biochim. Biophys. Acta, 249: 364 (1971).

4. Burg, M. B., and Orloff, J.: Oxygen consumption and active transport in separated renal tubules. Am. J. Physiol., 203: 327 (1962)

5. Chesney, R. W., and Jax, D. K.: Developmental aspects of renal $\beta$-amino acid transport. I. Ontogeny of taurine reabsorption and accumulation in renal rat cortex. Pediatr. Res., 13: 854 (1979).

6. Chesney, R. W., and Jax. D. K.: Developmental aspects of renal $\beta$-amino acid transport. II. Ontogeny of uptake and efflux processes and effect of anoxia. Pediatr. Res., 13: 861 (1979).

7. Chesney, R. W.. Jax, D. K.. Mohyuddin, F., and Scriver, C. R.: In vitro use of polythylene- $\left(1,2^{14} \mathrm{C}\right)$-glycol to measure extracellular space in renal cortex slices from neonatal, immature and adult animals. Renal Physiol.. I: 166 (1978).

8. Chesney, R. W.. Jax, D. K., Scriver, C. R., and Mohyuddin, F.: In: A. Barbeau, R. Huxtable: Taurine and Neurological Disorders. pp. 73-93 (Raven Press, New York, 1978)

9. Chesney, R. W., Scriver, C. R., and Mohyuddin, F.: Localization of the membrane defect in transport of taurine by parallel studies in vivo and in vitro in hypertaurinuric mice. J. Clin. Invest., 57: 183 (1976)

10. Friedman, A. L., Jax, D. K., and Chesney, R. W.: $\beta$-Amino acid transport in isolated tubule segments. Renal Physiol., 2: 21 (1980).

11. Mohyuddin, F., and Scriver, C. R.: Amino acid transport in mammalian kidney: multiple systems for imino acids and glycine in rat kidney. Am. J. Physiol. 219: 1 (1970).

12. Reynolds, R., Roth, K. S., Hwang. S. M., and Segal, S.: On the development of glycine systems by rat renal cortex. Biochim. Biophys. Acta, 5II: 274 (1978).

13. Roth, K. S., Hwang. S. M., London, J. W., and Segal, S.: Ontogeny of glycine transport in isolated rat renal tubules. Am. J. Physiol., 233: F241 (1977).

14. Scriver. C. R., and Rosenberg. L. E.: In: Amino Acid Metabolism and Its Disorders. p. 39 (W. B. Saunders Co., Philadelphia, 1973).

15. Segal, S., Rea, C., and Smith, l.: Separate transport systems for sugars and amino acids in developing rat kidney cortex. Proc. Natl. Acad. Sci. U. S. A., 68: 372 (1971).

16. The authors thank Bonita Kopchinski for her expert secretarial assistance.

17. Requests for reprints should be addressed to: Dr. Aaron L. Frieuman. Department of Pediatrics, Center for Health Sciences, 600 Highland Avenue, Madison, WI 53792 (USA)

18. This research was supported in part by grants AM 19489-01 and HD 05484 from the National Institutes of Health. Dr. Chesney is the recipient of Research Career Development Award AM 00421.

19. Received for publication January 2, 1980

20. Accepted for publication May 1, 1980. 